\title{
Influence of Vertical Facial Growth Pattern on Herbst Appliance Effects in Prepubertal Patients: A Retrospective Controlled Study
}

\author{
Maria Rita Giuca, ${ }^{1}$ Marco Pasini (D), ${ }^{1}$ Sara Drago, ${ }^{2}$ Leonardo Del Corso, ${ }^{3}$ Arianna Vanni, ${ }^{4}$ \\ Elisabetta Carli, ${ }^{4}$ and Antonio Manni ${ }^{5}{ }^{5}$ \\ ${ }^{1}$ Department of Surgical, Medical, Molecular Pathology and Critical Area, Unit of Pediatric Dentistry, \\ University of Pisa, Pisa, Italy \\ ${ }^{2}$ Department of Orthodontics, School of Dentistry, University of Genova, Genova, Italy \\ ${ }^{3}$ Private Practice, Livorno, Italy \\ ${ }^{4}$ Private Practice, Pisa, Italy \\ ${ }^{5}$ Private Practice, Racale, Lecce, Italy \\ Correspondence should be addressed to Marco Pasini; dr.marcopasini@yahoo.it
}

Received 17 July 2019; Revised 24 November 2019; Accepted 9 December 2019; Published 11 January 2020

Academic Editor: Andrea Scribante

Copyright (C) 2020 Maria Rita Giuca et al. This is an open access article distributed under the Creative Commons Attribution License, which permits unrestricted use, distribution, and reproduction in any medium, provided the original work is properly cited.

\begin{abstract}
Introduction. The Herbst device is widely used for correction of class II malocclusions; however, most of the researches carried out on the Herbst appliance in literature do not take into account patients with a different mandibular divergence. The aim of this study was to investigate the effects of Herbst on dental and skeletal structures and to evaluate possible influence of vertical facial growth patterns. Methods. A retrospective study was conducted on lateral cephalograms of 75 growing patients (mean age: $9.9 \pm 1.9$ years) with class II malocclusion treated with Herbst. Subjects were divided into 3 groups using the mandibular divergence index (SN and GoMe angle). Cephalometric parameters were evaluated using the modified SO (sagittal occlusion) Pancherz's analysis. A statistical analysis was conducted to evaluate differences among groups using ANOVA. Results. Our study showed differences in response to treatment depending on patient's facial vertical growth pattern. Cranial base angle and mandibular rotation were significantly different $(p<0.05)$ between hypodivergent patients and normodivergent patients and between hypodivergent and hyperdivergent subjects. Conclusion. Hypodivergent patients increased their mandibular divergence during treatment to a greater extent than normodivergents; moreover, hyperdivergent patients exhibited a decreased mandibular divergence at the end of the treatment.
\end{abstract}

\section{Introduction}

Bilateral class II malocclusion represents one of the main orthodontic problems affecting the world population, and it has been observed that this condition affects $27.2 \%$ of English adolescents [1], 36.3\% of Italian adolescents [2], about $15 \%$ of the total United States population [3], and $27.0 \%$ of Chinese children [4].

This sagittal malocclusion can be skeletal, dental, or combined. In particular, in the great majority of cases (about $75 \%$ ), the skeletal component is affected [5].

The Herbst device is one of the most common appliances for the treatment of skeletal and dental class II, consisting of a piston and a tube anchored to orthodontic bands (or to splints or to cobalt/chrome fusions), which keeps the jaw in a protracted position 24 hours a day [6] through a bilateral telescopic mechanism.

The advantages include the following: high treatment speed (average treatment time 6-8 months), reduced request for patient's compliance, and effectiveness both on the dental and skeletal component [7].

The effects on the dental component include a distalisation of the upper dental arch and a mesialisation of the lower dental arch [8], while the effects on the skeletal component include a decreased growth of the maxilla [9] and a stimulation of the mandibular growth with an increase 
in the average length at the end of treatment greater than 2 $3 \mathrm{~mm}$ [10]. The mechanism permits vertical opening movements and effect on the vertical tooth position [11], and the skeletal effect is most pronounced during puberty rather than before [12].

The main disadvantage of the Herbst consists in a proclination of lower incisors due to anchorage loss in different amounts relative to the type of Herbst used [13]; various modifications of the original orthodontic appliance have been proposed, but none has been able to completely prevent proclination of mandibular incisors [13-15]. Most of the studies carried out on the Herbst appliance do not take into account patients with a different mandibular divergence [15], which affects chin position [16], the direction of the condylar growth [17], and the shape of the jaw [18].

Variation in the mandibular divergence with other orthodontic appliances for class II malocclusions has been investigated in a recent systematic review [19].

The aim of this study was to investigate the effect of the Herbst appliance on dental and skeletal levels and to evaluate the existing differences between patients with different vertical growth patterns.

\section{Materials and Methods}

A retrospective study was conducted on lateral cephalograms of consecutive patients previously treated in a private office (Lecce, Italy) within the past 5 years: from January 2014 to January 2019.

Sample size calculation was performed; estimate of standard deviation was based on data obtained from other 10 subjects who were followed in a preliminary study, considering mandibular divergence as the primary outcome. In order to compare two means with a power of $80 \%$, a size of the test of 5\%, a standard deviation of 1.5, and a difference of 1.2, the sample size required 25 patients in each group.

A total of 75 lateral cephalograms of patients with a skeletal class II and treated with Herbst appliance (35 males and 40 females; average age at the start of treatment $9.9 \pm 1.9$ years; average Herbst treatment duration $9.7 \pm 1.6$ months) were included in this study (test group).

The test group was compared with a control group of 75 untreated subjects, obtained from the University of Michigan Growth Study Center, the Bolton-Brush Growth study center, the University of Toronto Burlington Growth Study, the University of Oklahoma Denver Growth Study, the Oregon Growth Study, the Iowa Facial Growth Study, and the UOP Mathews Growth Study, matched for similar vertical relationships, sex, and skeletal age.

All procedures were conducted according to the principles expressed in the Declaration of Helsinki (1964), and a written consent (signed by parents or legal guardians) to participate in the study was obtained at the beginning of the orthodontic treatment.

The inclusion criteria were as follows: lateral cephalograms taken before and after Herbst treatment, presence of a permanent dentition or late mixed dentition, presence of bilateral angle class II division 1 malocclusion, and presence of mandibular deficiency and normal upper jaw. Exclusion criteria were as follows: presence of serious skeletal malformations, patients with systemic disease, patients undergoing a drug therapy that may cause skeletal abnormalities, and patients with agenesis and/or premature loss of permanent teeth. Lateral cephalograms were divided into 3 groups using the mandibular divergence index, measured on lateral cephalograms at the beginning of the treatment: angle between the straight lines SN (Sella-Nasion) and GoMe (Gonion-Menton).

All subjects with SNGoMe values less than or equal to $26.5^{\circ}$ were considered as belonging to the hypodivergent group, all subjects with SNGoMe values between $26.5^{\circ}$ and $36.5^{\circ}$ were considered as belonging to the normodivergent group, and all subjects with SNGoMe values greater than or equal to $36.5^{\circ}$ were considered as belonging to the hyperdivergent group.

The test group consisted of three different subgroups: group 1 included 25 hypodivergent subjects ( 12 males and 13 females) with an average age at the start of treatment of $10.6 \pm 2.0$ years and a mean duration of Herbst treatment of $9.6 \pm 1.9$ months.

Group 2 included 25 normodivergent subjects (11 males and 14 females) with an average age at the beginning of treatment of $9.8 \pm 1.9$ years and a mean duration of orthodontic treatment of $9.5 \pm 1.7$ months.

Group 3 included 25 hyperdivergent subjects (12 males and 13 females) with a mean age at the start of treatment of $9.4 \pm 1.8$ years and an average duration of treatment of $9.9 \pm 1.3$ months. Each subgroup was compared with three different control groups of 25 lateral cephalometrics, matched with the test subgroup for similar SNGoMe value, sex, and skeletal age that was assessed with cervical vertebral maturation staging [20].

2.1. Cephalometric Parameters. The investigation of the Herbst appliance effects at the dental and skeletal levels was performed on lateral cephalograms using the modified SO (sagittal occlusion) Pancherz's cephalometric analysis.

This analysis was carried out by transferring the lines occlusal line (OL) and occlusal perpendicular line (OLp) through the Sella from pretreatment lateral cephalogram to the posttreatment lateral cephalogram by superimposing skeletal stable structures of the anterior cranial base. Modified SO Pancherz's cephalometric analysis included the following parameters, that are not considered in traditional SO Pancherz analysis: skeletal divergence, skeletal class, and lower incisor inclination (Figure 1).

Cephalograms were performed with teeth in centric occlusion, with relaxed lips and head oriented parallel to the floor according to the Frankfurt plane.

For each patient of the test group, two lateral cephalograms were included: pretreatment (T1) and posttreatment (T2).

Cephalometric analysis was performed by a single operator using Delta-Dent ${ }^{\circledR}$ software (Orthopiù SRL).

2.2. Statistical Analysis. All linear and angular measurements were approximated to the nearest $0.1 \mathrm{~mm}$ and $0.1^{\circ}$, 


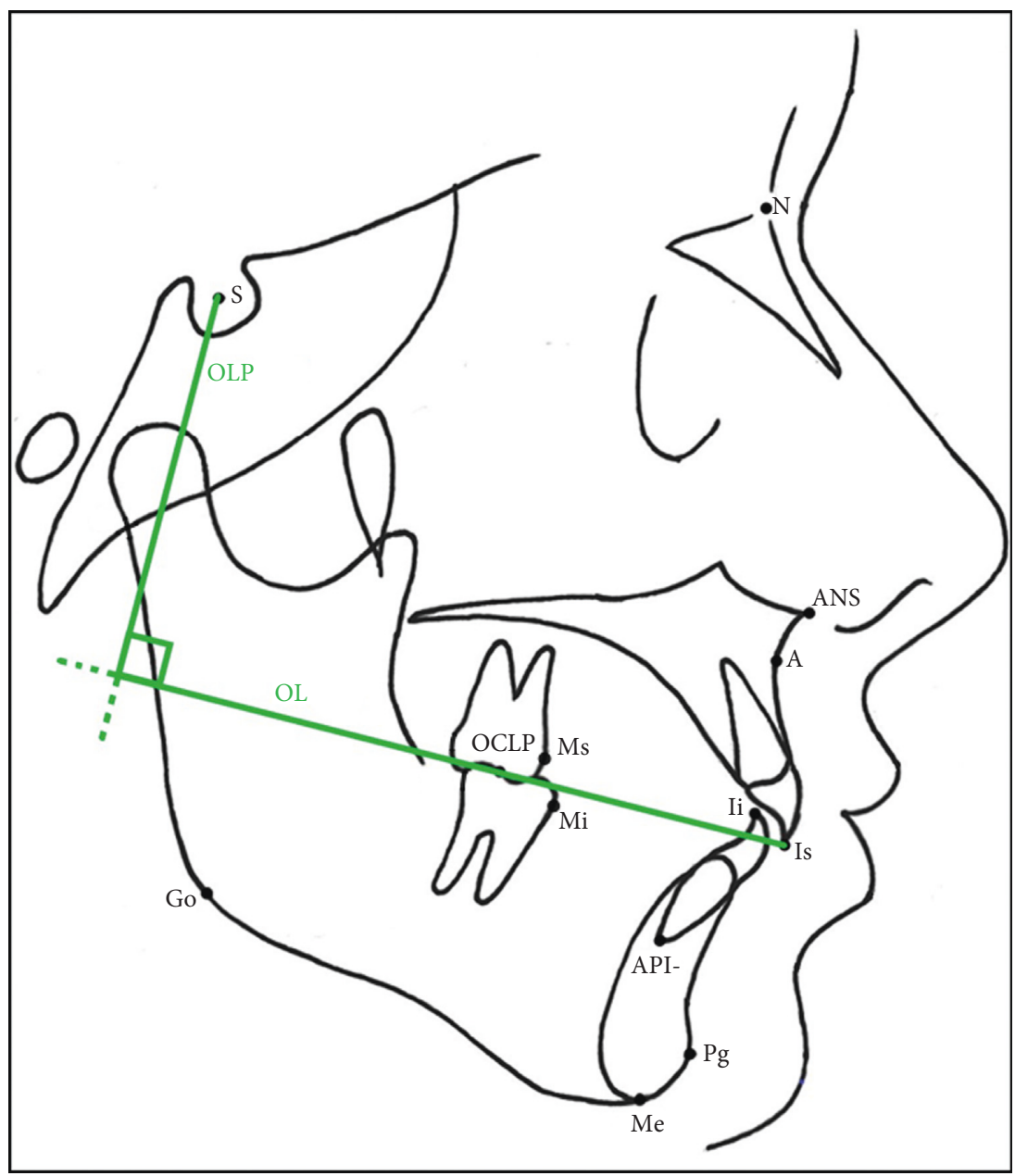

Figure 1: Modified SO Pancherz analysis. Reference points and lines: Sella (S), Nasion (N), subnasal (A), pogonion (Pg), Gonion (Go), Menton (Me), articular (Ar), anterior nasal spine (ANS), maxillary incisal (Is), mandibular incisal (Ii), lower incisal apex (API), posterior occlusal (OCLP), maxillary molar (Ms), mandibular molar (Mi), occlusal line (OL), and occlusal line perpendicular (OLP).

respectively. Dahlberg's formula was adopted after measuring each lateral cephalogram twice, with 14 days between each measurement; the method error was less than $0.5 \mathrm{~mm}$ and 1 degree (intraoperator reliability).

A blinded statistical analysis was performed. Data were checked for normality using the Shapiro-Wilk test. Continuous variables are given as means and standard deviations (SD), whereas categorical variables were given as number and/or percentage of subjects. The thirteen cephalometric parameters were considered as primary outcome measurements. Outcome baseline differences among treatment groups were tested by one-way ANOVA. In order to investigate the associations of the outcome parameters with divergence groups, the one-way ANOVA was performed again on the differences after-before for each group. A paired $t$-test was performed to observe intragroup differences. Subsequently, an independent samples $t$-test was adopted to evaluate the differences between each group and the controls.

The estimated $p$ values were adjusted for multiple comparisons by the Bonferroni correction method, and when the adjusted $p$ value was less than 0.05 , the differences were selected as significant. Data were acquired and analysed in R v3.4.4 software environment.

\section{Results}

No significant differences between groups were detected at baseline except for SNGoMe, lower incisor axis inclination, ANNPg, and skeletal discrepancy $(p<0.001$, Table 1$)$.

Table 2 shows for each treatment group any difference over time in all measurements; the ANOVA assessed a significant difference over time among groups for the following parameters: Ii-Olp and SNGoMe.

Significant intragroup variations from $\mathrm{T} 1$ to $\mathrm{T} 2$ in the total sample and in the three test subgroups are summarized in Table 3.

Herbst therapy has determined in the total sample a slight retreat of the upper maxilla, but no significant difference was observed at the end of the treatment. On the contrary, a significant advancement of the lower jaw with a reduction of skeletal discrepancy and improvement of ANPg angle was found after the Herbst treatment $(p<0.05)$. 
TABLE 1: Baseline characteristics in whole population $(N=75)$.

\begin{tabular}{|c|c|c|c|c|c|c|}
\hline Outcome variables & $\begin{array}{l}\text { Total mean } \\
\quad(S D)\end{array}$ & $\begin{array}{l}\text { Hypodivergent } \\
\text { mean (SD) }\end{array}$ & $\begin{array}{c}\text { Group } \\
\text { Normodivergent } \\
\text { mean }(\mathrm{SD})\end{array}$ & $\begin{array}{l}\text { Hyperdivergent } \\
\text { mean (SD) }\end{array}$ & $\begin{array}{c}p \\
\text { value }\end{array}$ & $\begin{array}{c}\text { Pairwise } \\
\text { comparisons }\end{array}$ \\
\hline $\mathrm{A} / \mathrm{Olp}$ & $69.91(4.47)$ & $69.68(5.25)$ & $70.38(4.46)$ & $69.67(3.71)$ & 0.817 & \\
\hline $\mathrm{Pg} / \mathrm{Olp}$ & $69.97(5.87)$ & 70.89 (6.38) & $70.13(6.19)$ & $68.88(5.02)$ & 0.481 & \\
\hline Is/Olp & $77.60(4.86)$ & $76.94(6.06)$ & $77.79(4.43)$ & 78.08 (3.95) & 0.693 & \\
\hline Ii/Olp & $70.29(5.42)$ & $70.32(6.23)$ & $70.19(5.27)$ & $70.36(4.90)$ & 0.993 & \\
\hline Ms/Olp & $36.53(4.54)$ & $36.78(5.14)$ & $36.68(4.79)$ & $36.13(3.74)$ & 0.864 & \\
\hline $\mathrm{Mi} / \mathrm{Olp}$ & $34.84(5.39)$ & $34.84(6.35)$ & $34.78(5.12)$ & $34.92(4.80)$ & 0.996 & \\
\hline $\mathrm{SN}^{\wedge} \mathrm{GoMe}$ & $32.67(5.97)$ & $25.68(2.31)$ & $33.09(2.02)$ & $39.24(2.15)$ & $<0.001$ & $\begin{array}{c}\text { Hypo vs. hyper: } \\
<0.001 \\
\text { Hypo vs. normo: } \\
<0.001 \\
\text { Hyper vs. normo: } \\
<0.001\end{array}$ \\
\hline $\begin{array}{l}\text { Lower incisor axis } \\
\text { inclination }\end{array}$ & $100.26(6.57)$ & $104.62(6.56)$ & $99.54(4.46)$ & $96.62(6.00)$ & $<0.001$ & $\begin{array}{c}\text { Hypo vs. hyper: } \\
<0.001 \\
\text { Hypo vs. normo: } \\
<0.001 \\
\text { Hyper vs. normo: } \\
0.2315\end{array}$ \\
\hline ANNPg & $4.78(2.30)$ & $3.35(2.01)$ & $5.40(1.93)$ & $5.59(2.32)$ & $<0.001$ & $\begin{array}{c}\text { Hypo vs. hyper: } \\
<0.001 \\
\text { Hypo vs. normo: } \\
<0.001 \\
\text { Hyper vs. normo: } \\
1.00\end{array}$ \\
\hline Skeletal discrepancy & $-0.07(2.68)$ & $-1.24(2.67)$ & $0.24(2.78)$ & $0.79(2.21)$ & 0.019 & $\begin{array}{c}\text { Hypo vs. hyper: } \\
0.02 \\
\text { Hypo vs. normo: } \\
0.13 \\
\text { Hyper vs. normo: } \\
1.00\end{array}$ \\
\hline Overjet & $7.32(2.47)$ & $6.70(2.51)$ & $7.55(2.64)$ & $7.72(2.23)$ & 0.298 & \\
\hline Molar relation & $1.69(1.92)$ & $1.96(2.14)$ & $1.90(1.65)$ & $1.21(1.93)$ & 0.312 & \\
\hline
\end{tabular}

Results are expressed as mean (standard deviation); $p$ value = one-way ANOVA; $p$ value, pairwise comparisons: $p$ values adjusted by using the Bonferroni method.

Moreover, orthodontic treatment resulted in a slight retreat of the upper central incisor even if the difference was not significant $(p>0.05 .05)$, a marked advancement of the lower central incisor $(p<0.05)$, and a marked reduction of overjet and molar relation $(p<0.05)$.

In the total sample, a loss of dental anchorage with an increased lower incisor inclination at the end of the treatment $(p<0.05)$ and a mean increase in cranial base-mandible angle (SN/GoMe) was observed.

Cephalometric changes (T2-T1) in the three subgroups are reported in Table 4 (hypodivergents vs. controls), Table 5 (normodivergent vs. controls), and Table 6 (hyperdivergent vs. controls).

Hypodivergent patients showed an increased mandibular divergence at the end of the therapy in comparison to the control group $(p<0.05)$, normodivergent subjects did no show significant changes in divergence in comparison to the controls $(p>0.05)$, and hyperdivergents showed a decrease in $\mathrm{SN} / \mathrm{GoMe}$ angle in comparison to the control group $(p<0.05)$.

\section{Discussion}

Based on the results obtained in this study, it is possible to notice that the Herbst treatment was effective for the resolution of class II malocclusion in all groups.

In fact, correction of sagittal dental class was obtained in all patients treated, with a decrease in overjet, skeletal class angle, skeletal discrepancy, and molar relation.

These results were obtained in all patients through a distalisation of the upper arch and a mesialisation of the lower arch, and these results are consistent with those of previous studies $[8,10,17,21-23]$. A slight high-pull headgear effect on the maxillary complex was found in the total sample, while a significant advancement of the mandible was observed (hypodivergents exhibited a slight lower mandibular advancement in comparison to normodivergent and hyperdivergent groups), and these results are in accordance with those of previous studies; Pancherz and Anehus-Pancherz found that the sagittal maxillary jaw base position seemed unaffected by therapy [24]. An increase in 
TABle 2: One-way ANOVA results to evidence any difference over time between groups.

\begin{tabular}{|c|c|c|c|c|c|c|}
\hline Outcome variables & $\begin{array}{l}\text { Total mean } \\
\text { (SD) }\end{array}$ & $\begin{array}{l}\text { Hypodivergent } \\
\text { mean (SD) }\end{array}$ & $\begin{array}{c}\text { Group } \\
\text { Normodivergent } \\
\text { mean }(\mathrm{SD})\end{array}$ & $\begin{array}{l}\text { Hyperdivergent } \\
\text { mean }(\mathrm{SD})\end{array}$ & $\begin{array}{c}p \\
\text { value }\end{array}$ & $\begin{array}{c}\text { Pairwise } \\
\text { comparisons }\end{array}$ \\
\hline $\mathrm{A} / \mathrm{Olp}$ & $0.18(1.58)$ & $0.35(1.92)$ & $-0.23(1.32)$ & $0.40(1.42)$ & 0.296 & \\
\hline $\mathrm{Pg} / \mathrm{Olp}$ & $2.33(2.19)$ & $2.11(2.31)$ & $2.41(2.02)$ & $2.46(2.31)$ & 0.837 & \\
\hline Is/Olp & $-0.43(2.04)$ & $0.17(2.42)$ & $-0.64(1.80)$ & $-0.82(1.78)$ & 0.190 & \\
\hline Ii/Olp & $0.36(3.57)$ & $-2.72(2.74)$ & $4.00(1.91)$ & $-0.19(2.03)$ & $<0.001$ & $\begin{array}{c}\text { Hypo vs. hyper: } \\
<0.001 \\
\text { Hypo vs. normo: } \\
<0.001 \\
\text { Hyper vs. normo: } \\
\quad<0.001\end{array}$ \\
\hline $\mathrm{Ms} / \mathrm{Olp}$ & $-1.36(2.20)$ & $-1.61(2.41)$ & $-1.44(2.53)$ & $-1.03(1.61)$ & 0.640 & \\
\hline Mi/Olp & $4.07(2.52)$ & $3.56(2.91)$ & $4.36(2.42)$ & $4.28(2.20)$ & 0.473 & \\
\hline $\mathrm{SN}^{\wedge} \mathrm{GoMe}$ & $0.28(2.77)$ & $1.66(2.53)$ & $-0.01(2.33)$ & $-0.81(2.91)$ & 0.004 & $\begin{array}{c}\text { Hypo vs. hyper: } \\
0.004 \\
\text { Hypo vs. normo: } \\
0.077 \\
\text { Hyper vs. normo: } \\
0.842 \\
\end{array}$ \\
\hline $\begin{array}{l}\text { Lower incisor axis } \\
\text { inclination }\end{array}$ & $5.58(4.77)$ & $4.51(3.84)$ & $5.47(5.52)$ & $6.77(4.72)$ & 0.246 & \\
\hline AN^NPg & $-1.49(1.72)$ & $-1.20(1.27)$ & $-2.05(2.16)$ & $-1.24(1.52)$ & 0.142 & \\
\hline Skeletal discrepancy & $-2.52(2.28)$ & $-3.08(2.66)$ & $-2.43(2.09)$ & $-2.06(1.99)$ & 0.281 & \\
\hline Overjet & $-4.38(2.21)$ & $-3.62(2.07)$ & $-4.64(2.19)$ & $-4.87(2.26)$ & 0.102 & \\
\hline Molar relation & $-5.02(5.54)$ & $-5.53(3.22)$ & $-4.21(8.76)$ & $-5.31(2.50)$ & 0.672 & \\
\hline
\end{tabular}

Pairwise comparisons: $p$ values adjusted by using Bonferroni method. In the first column, differences after-before for each group are given.

TABLE 3: Intragroup $p$ values (test group: T2-T1).

\begin{tabular}{lcccc}
\hline & Total sample (75) & Hypodivergent (25) & Normodivergent (25) & Hyperdivergent (25) \\
& $p$ & $p$ & $p$ & 0.88 \\
A/Olp & 0.90 & 0.81 & 0.14 & 0.85 \\
Pg/Olp & $0.02^{*}$ & 0.50 & 0.76 & 0.11 \\
Is/Olp & 0.45 & 0.74 & $0.01^{*}$ & 0.50 \\
Ii/Olp & $0.01^{*}$ & 0.10 & 0.30 & $0.01^{*}$ \\
Ms/Olp & 0.07 & 0.20 & $0.01^{*}$ & 0.38 \\
Mi/Olp & $0.01^{*}$ & 0.07 & 0.93 & $0.01^{*}$ \\
SNGoMe & 0.97 & 0.05 & $0.01^{*}$ & 0.37 \\
Lower incisor axis inclination & $0.01^{*}$ & $0.04^{*}$ & $0.01^{*}$ & $0.01^{*}$ \\
ANNPg & $0.01^{*}$ & 0.06 & $0.01^{*}$ & 0.07 \\
Skeletal discrepancy & $0.01^{*}$ & $0.04^{*}$ & $0.01^{*}$ & $0.01^{*}$ \\
Overjet & $0.01^{*}$ & $0.01^{*}$ & $0.01^{*}$ & $0.01^{*}$ \\
Molar relation & $0.01^{*}$ & $0.01^{*}$ & & $0.01^{*}$ \\
\hline
\end{tabular}

${ }^{*} p<0.05$.

the inclination of the lower incisor, with respect to the mandibular base, was recorded in all groups, and a greater mandibular incisor anchorage loss was observed in the hyperdivergent group, while hypodivergent exhibited the lower mandibular incisor anchorage loss. However, no significant differences in mandibular advancement were found among groups.

Normodivergents did not show changes in divergence; hypodivergent patients slightly increased their mandibular divergence during orthodontic treatment, while hyperdivergent patients showed a slight decrease in the mandibular divergence.
In literature, a significant alteration was found in mandibular divergence at the end of the Herbst treatment in a limited number of studies [25-27], while other previous studies showed a significant change of SN/GoMe at the end of orthodontic therapy [28].

It was recorded that, after Herbst treatment, the upper molars moved mesially, the occlusal plane slightly closed, and the palatal plane tipped downward [24].

Ruf and Pancherz stated that the mandibular plane angle was slightly affected by Herbst appliance treatment, and at the end of the orthodontic therapy, a continuous decrease in the mandibular plane angle was found [25]. 
TABLE 4: Hypodivergent patients versus controls, mean difference between posttreatment (T2) and pretreatment (T1).

\begin{tabular}{lccc}
\hline Parameter & Hypodivergent test mean $(\mathrm{SD})$ & Hypodivergent control mean $(\mathrm{SD})$ & $p$ value \\
\hline A/Olp & $0.35 \pm 1.92$ & $0.1 \pm 0.3$ & 0.5 \\
Pg/Olp & $2.11 \pm 2.31$ & $0.2 \pm 0.5$ & $<0.001$ \\
Is/Olp & $0.17 \pm 2.42$ & $0.1 \pm 0.4$ & 0.89 \\
Ii/Olp & $-2.72 \pm 2.74$ & $0.2 \pm 0.5$ & $<0.001$ \\
Ms/Olp & $-1.61 \pm 2.41$ & $0.2 \pm 0.4$ & $<0.001$ \\
Mi/Olp & $3.56 \pm 2.91$ & $0.2 \pm 0.3$ & $<0.001$ \\
SNGGoMe & $1.66 \pm 2.53$ & $-0.5 \pm 0.9$ & $<0.001$ \\
LII & $4.51 \pm 3.84$ & $0.1 \pm 0.3$ & $<0.001$ \\
AN`NPg & $-1.20 \pm 1.27$ & $0.2 \pm 0.3$ & $<.3$ \\
Skeletal discrepancy & $-3.08 \pm 2.66$ & $0.1 \pm 0.2$ & $<0.1$ \\
Overjet & $-3.62 \pm 2.07$ & $0.1 \pm 0.3$ & $<0.001$ \\
Molar relation & $-5.53 \pm 3.22$ & $0.1 \pm 0.4$ & $<0.001$ \\
\hline
\end{tabular}

TAвLE 5: Normodivergent patients versus controls, mean difference between posttreatment (T2) and pretreatment (T1).

\begin{tabular}{lccc}
\hline Parameter & Normodivergent test mean (SD) & Normodivergent control mean (SD) & $p$ value \\
\hline A/Olp & $-0.23 \pm 1.32$ & $0.2 \pm 0.5$ & 0.13 \\
Pg/Olp & $2.41 \pm 2.02$ & $0.4 \pm 0.7$ & $<0.001$ \\
Is/Olp & $-0.64 \pm 1.80$ & $0.3 \pm 0.4$ & 0.01 \\
Ii/Olp & $4.00 \pm 1.91$ & $0.2 \pm 0.4$ & $<0.001$ \\
Ms/Olp & $-1.44 \pm 2.53$ & $0.3 \pm 0.6$ & $<0.001$ \\
Mi/Olp & $4.36 \pm 2.42$ & $0.2 \pm 0.5$ & $<0.001$ \\
SN'GoMe & $-0.01 \pm 2.33$ & $0.2 \pm 0.4$ & 0.66 \\
LII & $5.47 \pm 5.52$ & $0.2 \pm 0.2$ & $<0.001$ \\
ANNNPg & $-2.05 \pm 2.16$ & $0.1 \pm 0.2$ & $<0.001$ \\
Skeletal discrepancy & $-2.43 \pm 2.09$ & $0.2 \pm 0.3$ & $<0.001$ \\
Overjet & $-4.64 \pm 2.19$ & $0.1 \pm 0.4$ & $<0.001$ \\
Molar relation & $-4.21 \pm 8.76$ & $0.1 \pm 0.3$ & $<0.001$ \\
\hline
\end{tabular}

TABle 6: Hyperdivergent patients versus controls, mean difference between posttreatment (T2) and pretreatment (T1).

\begin{tabular}{lccc}
\hline Parameter & Hyperdivergent test mean (SD) & Hyperdivergent control mean (SD) & $p$ value \\
\hline A/Olp & $0.40 \pm 1.42$ & $0.1 \pm 0.9$ & 0.38 \\
Pg/Olp & $2.46 \pm 2.31$ & $-0.2 \pm 1$ & $<0.001$ \\
Is/Olp & $-0.82 \pm 1.78$ & $0.1 \pm 0.8$ & 0.02 \\
Ii/Olp & $-0.19 \pm 2.03$ & $0.1 \pm 0.9$ & 0.51 \\
Ms/Olp & $-1.03 \pm 1.61$ & $0.2 \pm 0.7$ & 0.001 \\
Mi/Olp & $4.28 \pm 2.20$ & $0.2 \pm 0.8$ & $<0.001$ \\
SNGGoMe & $-0.81 \pm 2.91$ & $0.5 \pm 0.8$ & 0.03 \\
LII & $6.77 \pm 4.72$ & $0 \pm 0.1$ & $<0.001$ \\
ANNNPg & $-1.24 \pm 1.52$ & $0.2 \pm 0.6$ & $<0.001$ \\
Skeletal discrepancy & $-2.06 \pm 1.99$ & $0.1 \pm 0.5$ & $<0.001$ \\
Overjet & $-4.87 \pm 2.26$ & $0.1 \pm 0.4$ & $<0.001$ \\
Molar relation & $-5.31 \pm 2.50$ & $0.1 \pm 0.3$ & $<0.001$ \\
\hline
\end{tabular}

In a previous study, a significant difference of cranial base-mandibular angle was found between hypodivergent, normodivergent, and hyperdivergent patients [28], and the results showed that hypodivergent subjects tend to decrease this angle, while hyperdivergents tend to increase it. In fact, these authors observed that hypo- and hyperdivergent patients benefit from Herbst's headgear effect in the upper maxilla, while hyperdivergent patients exhibited a deleterious backward mandibular rotation. A possible explanation could be that cantilever Herbst appliance with full-coverage stainless steel crowns on the upper and lower first molars was used by Rogers et al. [28], while in the present study, a total acrylic splint extending from the first lower molar to the first contralateral molar was used to reinforce the anchorage. Furthermore, another possible explanation for the rotational differences between subjects with different vertical growth patterns could be the orofacial musculature function as patients with weak jaw musculature could exhibit a backward mandibular rotation.

Further studies conducted on a larger number of lateral cephalograms will be necessary to confirm the results of the present study. 


\section{Conclusion}

Our study showed differences in response to treatment with the Herbst appliance depending on patient's vertical growth pattern. Particularly, the changes in Ii/Olp over time were significantly different among groups $(p<0.001)$.

Moreover, the results exhibited that hypodivergent patients increased their mandibular divergence during treatment. Normodivergent patients showed very slight differences in mandibular divergence with no significant difference, while hyperdivergent patients exhibited a mandibular divergence decrease at the end of the Herbst treatment, and the difference among groups was significant $(p<0.05)$.

\section{Data Availability}

The data used to support the findings of this study are available from the corresponding author upon request.

\section{Conflicts of Interest}

The authors declare that there are no conflicts of interest regarding the publication of this paper.

\section{Supplementary Materials}

Cephalometric parameters and their description. (Supplementary Materials)

\section{References}

[1] T. D. Foster and A. J. Walpole Day, "A survey of malocclusion and the need for orthodontic treatment in a Shropshire school population," British Journal of Orthodontics, vol. 1, no. 3, pp. 73-78, 1974.

[2] L. Perillo, C. Masucci, F. Ferro, D. Apicella, and T. Baccetti, "Prevalence of orthodontic treatment need in southern Italian schoolchildren," The European Journal of Orthodontics, vol. 32, no. 1, pp. 49-53, 2010.

[3] W. R. Proffit, H. W. Fields Jr., and L. J. Moray, "Prevalence of malocclusion and orthodontic treatment need in the United States: estimates from the NHANES III survey," The International Journal of Adult Orthodontics and Orthognathic Surgery, vol. 13, no. 2, pp. 97-106, 1998.

[4] J. Yang, Y. Z. Li, Y. Liu, Q. Zhang, and X. Yuan, "Epidemiological survey of malocclusion in 8-9 year-old children in Qingdao Laoshan district," Shanghai Kou Qiang Yi Xue, vol. 28, no. 3, pp. 284-287, 2019, in Chinese.

[5] M. Milacic and M. Markovic, "A comparative occlusal and cephalometric study of dental and skeletal anteroposterior relationships," British Journal of Orthodontics, vol. 10, no. 1, pp. 53-54, 1983.

[6] D. B. d. A. Brito, J. F. C. Henriques, C. F. Fiedler, and G. Janson, "Effects of class II division 1 malocclusion treatment with three types of fixed functional appliances," Dental Press Journal of Orthodontics, vol. 24, no. 5, pp. 30-39, 2019.

[7] H. Pancherz, "The mechanism of class II correction in Herbst appliance treatment," American Journal of Orthodontics, vol. 82, no. 2, pp. 104-113, 1982.
[8] A. Manni, D. Lupini, and M. Cozzani, "Four TADs supported Herbst mechanics: a case report," International Orthodontics, vol. 17, no. 2, pp. 354-364, 2019.

[9] L. Wieslander, "Long-term effect of treatment with the headgear-Herbst appliance in the early mixed dentition. Stability or relapse?," American Journal of Orthodontics and Dentofacial Orthopedics, vol. 104, no. 4, pp. 319-329, 1993.

[10] N. G. Amuk, A. Baysal, R. Coskun, and G. Kurt, "Effectiveness of incremental vs. maximum bite advancement during Herbst appliance therapy in late adolescent and young adult patients," American Journal of Orthodontics and Dentofacial Orthopedics, vol. 155, no. 1, pp. 48-56, 2019.

[11] A. Atresh, L. H. S. Cevidanes, M. Yatabe et al., "Three-dimensional treatment outcomes in class II patients with different vertical facial patterns treated with the Herbst appliance," American Journal of Orthodontics and Dentofacial Orthopedics, vol. 154, no. 2, pp. 238-248.e1, 2018.

[12] S. Ruf and H. Pancherz, "When is the ideal period for Herbst therapy-early or late?," Seminars in Orthodontics, vol. 9, no. 1, pp. 47-56, 2003.

[13] H. Pancherz and K. Bjerklin, "Mandibular incisor inclination, tooth irregularity, and gingival recessions after Herbst therapy: a 32-year follow-up study," American Journal of Orthodontics and Dentofacial Orthopedics, vol. 146, no. 3, pp. 310-318, 2014.

[14] L. Hollender, A. Rönnerman, and B. Thilander, "Root resorption, marginal bone support and clinical crown length in orthodontically treated patients," The European Journal of Orthodontics, vol. 2, no. 4, pp. 197-205, 1980.

[15] P. H. Buschang and H. B. Jacob, "Mandibular rotation revisited: what makes it so important?," Seminars in Orthodontics, vol. 20, no. 4, pp. 299-315, 2014.

[16] M. B. LaHaye, P. H. Buschang, R. G. W. Alexander, and J. C. Boley, "Orthodontic treatment changes of chin position in class II division 1 patients," American Journal of Orthodontics and Dentofacial Orthopedics, vol. 130, no. 6, pp. 732-741, 2006.

[17] A. Björk and V. Skieller, "Facial development and tooth eruption. An implant study at the age of puberty," American Journal of Orthodontics, vol. 62, no. 4, pp. 339-383, 1972.

[18] M. K. Wang, P. H. Buschang, and R. Behrents, "Mandibular rotation and remodeling changes during early childhood," The Angle Orthodontist, vol. 79, no. 2, pp. 271-275, 2009.

[19] G. Perinetti, J. Primožič, L. Franchi, and L. Contardo, "Treatment effects of removable functional appliances in prepubertal and pubertal class II patients: a systematic review and meta-analysis of controlled studies," PLoS One, vol. 10, no. 10, Article ID e0141198, 2015.

[20] R. C. Santiago, L. F. de Miranda Costa, R. W. F. Vitral, M. R. Fraga, A. M. Bolognese, and L. C. Maia, "Cervical vertebral maturation as a biologic indicator of skeletal maturity," The Angle Orthodontist, vol. 82, no. 6, pp. 1123-1131, 2012.

[21] R. S. Croft, P. H. Buschang, J. D. English, and R. Meyer, “A cephalometric and tomographic evaluation of Herbst treatment in the mixed dentition," American Journal of Orthodontics and Dentofacial Orthopedics, vol. 116, no. 4, pp. 435-443, 1999.

[22] K. Hansen, H. Pancherz, and U. Hagg, "Long-term effects of the Herbst appliance in relation to the treatment growth period: a cephalometric study," The European Journal of Orthodontics, vol. 13, no. 6, pp. 471-481, 1991.

[23] H. Pancherz and K. Hensen, "Occlusal changes during and after Herbst treatment: a cephalometric investigation," The 
European Journal of Orthodontics, vol. 8, no. 4, pp. 215-228, 1986.

[24] H. Pancherz and M. Anehus-Pancherz, "The headgear effect of the Herbst appliance: a cephalometric long-term study," American Journal of Orthodontics and Dentofacial Orthopedics, vol. 103, no. 6, pp. 510-520, 1993.

[25] S. Ruf and H. Pancherz, "The effect of Herbst appliance treatment on the mandibular plane angle: a cephalometric roentgenographic study," American Journal of Orthodontics and Dentofacial Orthopedics, vol. 110, no. 2, pp. 225-229, 1996.

[26] E. Deen and M. G. Woods, "Effects of the Herbst appliance in growing orthodontic patients with different underlying vertical patterns," Australian Orthodontic Journal, vol. 31, no. 1, pp. 59-68, 2015.

[27] C. Turnock and M. G. Woods, "The Herbst appliance and the activator: influence of the vertical facial pattern," Australian Orthodontic Journal, vol. 32, no. 2, pp. 130-138, 2016.

[28] K. Rogers, P. M. Campbell, L. Tadlock, E. Schneiderman, and P. H. Buschang, "Treatment changes of hypo- and hyperdivergent class II Herbst patients," The Angle Orthodontist, vol. 88, no. 1, pp. 3-9, 2018. 


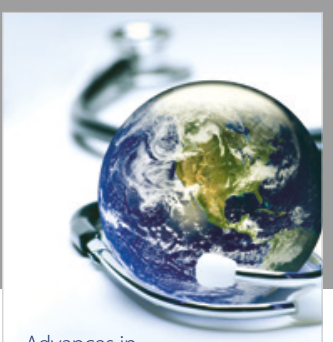

Advances in
Public Health

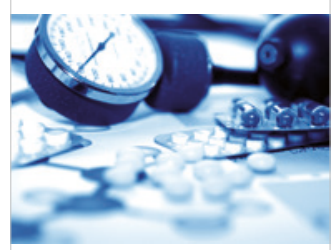

Case Reports in

Medicine

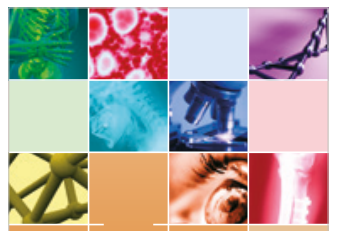

niernational Journal of

Biomaterials
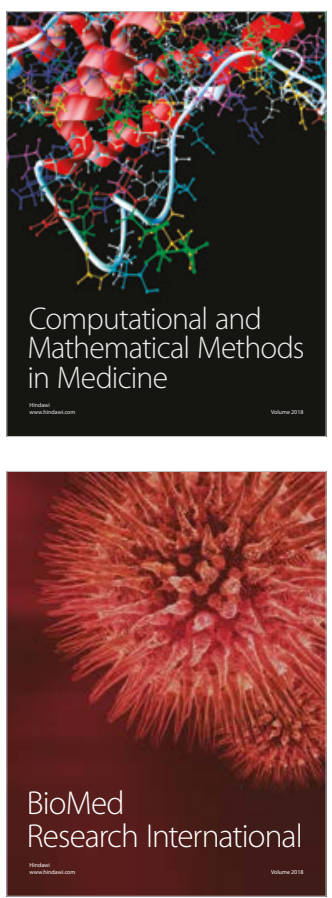

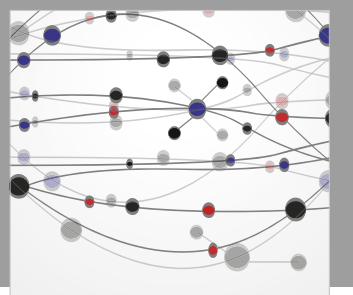

The Scientific World Journal Dentistry

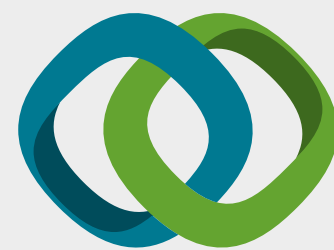

Hindawi

Submit your manuscripts at

www.hindawi.com
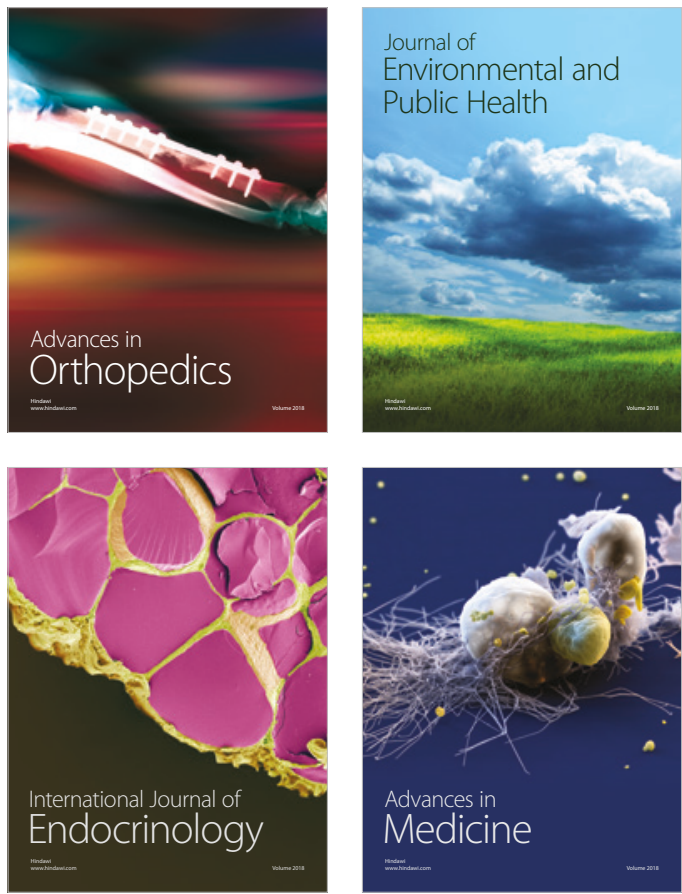
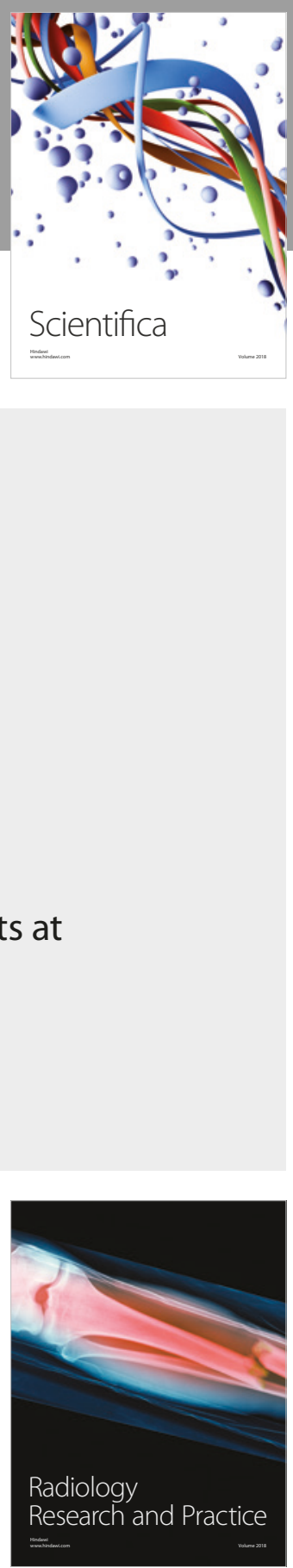

Scientifica

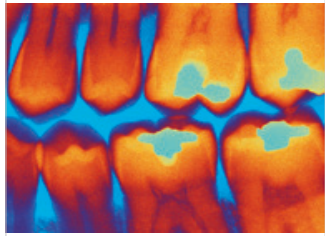

Case Reports in

Dentistry
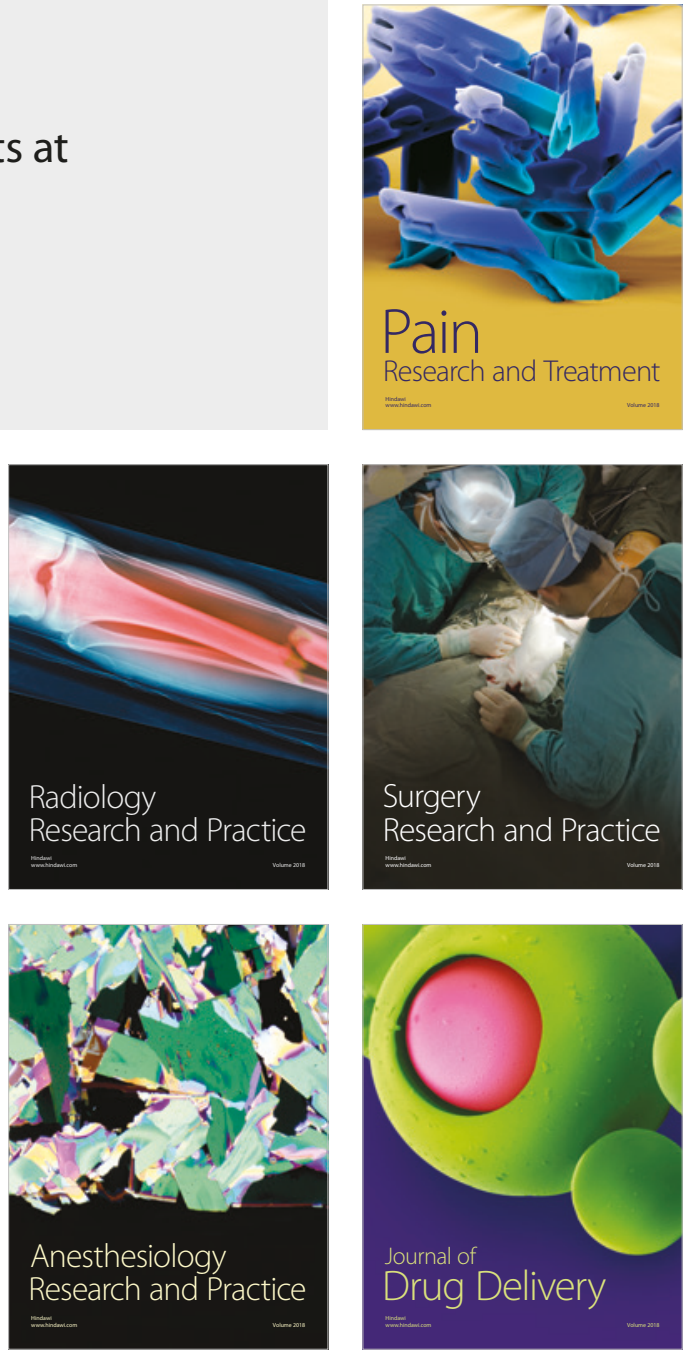